\title{
A simple method for removing the luminal epithelium of the mouse uterus for biochemical studies
}

\author{
Barbara Fagg*, L. Martin, L. Rogers, B. Clark and Valerie E. Quarmby \\ Department of Hormone Physiology, The Endocrine Group, Imperial Cancer Research Fund, \\ Lincoln's Inn Fields, London WC2A 3PX, U.K.
}

\begin{abstract}
Summary. The luminal epithelium of the mouse uterus was removed simply and rapidly by opening the uterine horns longitudinally and 'vortexing' them in buffer with glass balls. This procedure, which requires no specialized apparatus, was developed for use with uteri in different hormonal states, and 2 uterine horns/tube, 5 glass balls and vortexing for $2 \mathrm{~min}$ are suggested for routine use. Under these conditions, $79-100 \%$ of the cells were removed, yielding epithelial fractions of $65-90 \%$ purity. The suspension of cell constituents recovered contained intact nuclei which could be further purified. Extensive histological examination demonstrated that the other uterine tissues were minimally damaged.
\end{abstract}

\section{Introduction}

An understanding of the processes regulating ovum implantation requires detailed knowledge of the hormonal modulation of the metabolism of the uterine luminal epithelium. Such knowledge is unlikely to come from studies of whole uteri, since the luminal epithelium usually constitutes only a minor fraction of the uterine tissues (Martin, Finn \& Trinder, 1973), most of which respond differently to hormonal stimuli (Martin \& Finn, 1968).

The uterine epithelium consists of only a single layer of cells and therefore gentle procedures are required to remove it without damaging the stroma. Previous methods have involved scraping the luminal surface with a razor blade, glass rod (Alberga \& Baulieu, 1968) or dental lancet (Lee, 1973), pressing the uterine horns between glass plates (King \& Gordon, 1966; Heald, Govan \& O'Grady, 1975) and shearing the opened uteri in a Potter-Elvehjem homogenizer (Smith, Martin, King \& Vertes, 1970). However, little attention seems to have been directed towards the development of a method suitable for uteri in different hormonal states, or to the estimation of the extent of epithelial cell removal or the purity of the resultant epithelial fraction. Smith et al. (1970) and Pollard \& Martin (1975), by selectively labelling either the epithelium or the stroma with $\left[{ }^{3} \mathrm{H}\right]$ thymidine, reported that $75-85 \%$ and $80-100 \%$ respectively of nuclei in the epithelial fractions were derived from the luminal epithelium.

The methods of Smith et al. (1970) and Lee (1973) have been used routinely in this laboratory, but both procedures are lengthy and, since pressures are critical, epithelial separation was not always reproducible between operators. The present paper therefore describes a method developed to try to circumvent some of these problems.

\section{Materials and Methods}

\section{Animals and hormone treatments}

Adult female Swiss Schneider mice were ovariectomized and primed 2 weeks later with 3 daily injections of $100 \mathrm{ng}$ oestradiol-17 $\beta$ (Martin et al., 1973). The animals were then given no

* Present address: Swiss Institute for Experimental Cancer Research, 1066 Epalinges/Lausanne, Switzerland. 
further treatment (Group C), one injection of $50 \mathrm{ng}$ oestradiol-17及 6 days after the last priming injection (Group O) or 4 daily injections of $1 \mathrm{mg}$ progesterone (Days 3-6 after priming) with (Group PO) or without (Group P) $50 \mathrm{ng}$ oestradiol-17 3 on Day 6. Hormones were administered subcutaneously in $50 \mu \mathrm{l}$ (oestradiol-17ß) or $100 \mu \mathrm{l}$ (progesterone) arachis oil.

\section{Removal of the uterine epithelium}

Animals were killed 7 days after the last priming injection, i.e. $24 \mathrm{~h}$ after the injection on Day 6. Using fine scissors, each uterine horn was cut transversely, anterior to the cervix, slit open longitudinally in situ and then carefully freed from the mesentery. Two or 5 uterine horns were placed in a $15 \mathrm{ml}$ test-tube containing $1 \mathrm{ml}$ ice-cold buffer (unless stated otherwise, the buffer used was phosphate-buffered saline, pH 7.4 (PBS): Dulbecco \& Vogt, 1954) and 3 or 5 smooth glass balls ( $5 \mathrm{~mm}$ diameter: Scientific Supplies, London). Subsequent procedures were carried out at $4^{\circ} \mathrm{C}$. The contents of the tube were mixed for 2 min using a laboratory vortex mixer (Rotamixer: Hook \& Tucker Ltd, Croydon, Surrey) operated at its fastest speed. The 'residual' uterine horns were removed from the buffer with forceps and were fixed for histology as described below. The residual fluid was termed the 'epithelial fraction'. The DNA content of this fraction was estimated by the mithramycin technique of Hill \& Whatley (1975), using calf thymus DNA (Sigma) as standard.

\section{Preparation of nuclei from the epithelial fraction}

A nuclear pellet was prepared by centrifuging the epithelial fraction at $800 g_{\mathrm{av}}$ for $10 \mathrm{~min}$ at $4^{\circ} \mathrm{C}$; in some cases, centrifugation was preceded by homogenization in a Potter-Elvehjem teflon-glass homogenizer. In some experiments, the nuclear pellet was resuspended in a solution of $2 \mathrm{M}$-sucrose and $3 \mathrm{mM}-\mathrm{CaCl}_{2}$ and centrifuged at $50000 \mathrm{~g}_{\mathrm{av}}$ for $30 \mathrm{~min}$.

\section{Microscopic examination}

For light microscopy, each uterine horn was pinned to a uniform length of $2.5 \mathrm{~cm}$ in Bouin's fixative; $5 \mu \mathrm{m}$ paraffin-wax sections were cut from the mid-region and stained with Cole's

\section{PLATE 1}

Fig. 1. Transverse section of a uterine horn before removal of the epithelium. $\times 64$.

Fig. 2. Part of a transverse section (typical of a large number examined) of a uterine horn after removal of the epithelium. The stroma and myometrium are intact. $\times 64$.

Fig. 3. Transmission electron micrograph of the subepithelial stroma after the epithelium was removed by vortexing in $0.25 \mathrm{M}$-sucrose $+3 \mathrm{mM}-\mathrm{CaCl}_{2}$. The basement membrane (arrows), endothelial cells and stromal nuclei are intact, although some damage to the stromal cells is apparent. $\times 1100$

Fig. 4. As in Fig. 3, but the vortexing buffer was $10 \mathrm{~mm}-\mathrm{Tris}-\mathrm{HCl}(\mathrm{pH} \mathrm{7.4)}+1 \mathrm{~mm}$-EDTA. The basement membrane (arrow) is intact, but the stromal cells and their nuclei have been disrupted with release of chromatin. $\times 1100$.

Fig. 5. Scanning electron micrograph of the luminal and cut surfaces of a uterine horn after the removal of the epithelium. The stromal surface is smooth, although 2 small tears are visible (arrows). The necks of glands and the rough and fibrous cut surface of the stroma can be seen. $\times 340$.

Fig. 6. Transmission electron micrograph of a nuclear pellet obtained by centrifugation ( $\left.800 \boldsymbol{g}_{\mathrm{av}}\right)$ of the epithelial fraction, which was prepared in $0.25 \mathrm{M}$-sucrose $+3 \mathrm{mM}-\mathrm{CaCl}_{2}+0.7 \%(\mathrm{v} / \mathrm{v})$ Nonidet. The nuclei have lost their outer membranes but are otherwise intact. There is little or no contamination with other cellular debris. $\times 2000$. 


\section{PLATE 1}
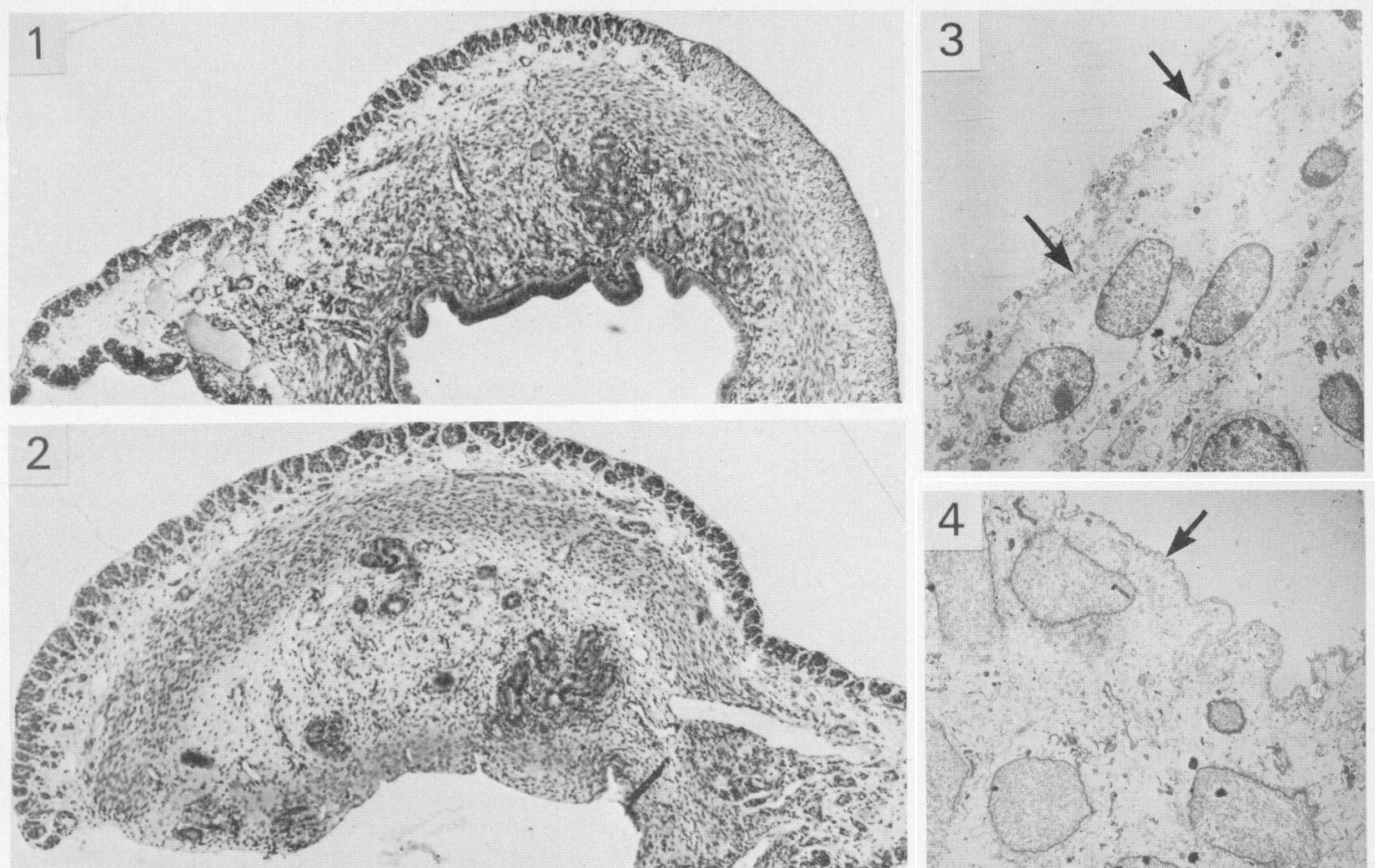
haematoxylin and eosin. The percentage of luminal epithelial cells which had been removed by vortexing was estimated by a second operator who scored the sections 'blind'.

Sections for transmission electron microscopy were prepared from 'residual' uteri and nuclear pellets which were fixed in $2.5 \%$ glutaraldehyde in PBS, post-fixed in $1 \%$ osmium tetroxide and stained in $0.5 \%$ uranyl acetate. For scanning electron microscopy, 'residual' uteri were prepared as described by Kelley, Dekker \& Bluemink (1974) and Cohen (1974).

\section{Results}

\section{Development of the method}

A high percentage (79-100\%) of the epithelium of uteri from mice in Groups $P$ and $C$ was removed under any of the conditions tested, but more extreme conditions were required for those in Groups PO and O, i.e. round-bottomed tubes and 5 glass balls (Table 1). There was little difference in the results when 2 or 5 uterine horns were used per tube. Additional experiments (data not shown) indicated that there was no further improvement in the amount of epithelium removed when (a) uterine horns were incubated for $10 \mathrm{~min}$ before vortexing or (b) the vortexing time was increased from 2 to $5 \mathrm{~min}$.

Table 1. The effects of tube shape and number of glass balls and uterine horns per tube on the percentage removal of epithelium from mouse uteri after various hormone treatments

\begin{tabular}{|c|c|c|c|c|c|c|c|c|c|}
\hline \multirow[b]{2}{*}{$\begin{array}{c}\text { No. of } \\
\text { uterine } \\
\text { horns/tube }\end{array}$} & \multirow[b]{2}{*}{$\begin{array}{l}\text { Tube } \\
\text { shape }\end{array}$} & \multicolumn{2}{|c|}{ Group PO } & \multicolumn{2}{|c|}{ Group O } & \multicolumn{2}{|c|}{ Group P } & \multicolumn{2}{|c|}{ Group C } \\
\hline & & $\begin{array}{c}3 \\
\text { balls/ } \\
\text { tube }\end{array}$ & $\begin{array}{c}5 \\
\text { balls/ } \\
\text { tube }\end{array}$ & $\begin{array}{c}3 \\
\text { balls/ } \\
\text { tube }\end{array}$ & $\begin{array}{c}5 \\
\text { balls/ } \\
\text { tube }\end{array}$ & $\begin{array}{c}3 \\
\text { balls/ } \\
\text { tube }\end{array}$ & $\begin{array}{c}5 \\
\text { balls/ } \\
\text { tube }\end{array}$ & $\begin{array}{c}3 \\
\text { balls/ } \\
\text { tube }\end{array}$ & $\begin{array}{c}5 \\
\text { balls/ } \\
\text { tube }\end{array}$ \\
\hline 5 & $\begin{array}{l}\text { Round } \\
\text { Conical }\end{array}$ & $\begin{array}{l}89 \pm 9 \\
64 \pm 6\end{array}$ & $\begin{array}{l}79 \pm 9 \\
73 \pm 12\end{array}$ & $\begin{array}{l}83 \pm 6 \\
28 \pm 9\end{array}$ & $\begin{array}{r}100 \pm 0 \\
61 \pm 11\end{array}$ & $\begin{array}{l}95 \pm 4 \\
91 \pm 6\end{array}$ & $\begin{array}{l}99 \pm 1 \\
99 \pm 1\end{array}$ & $\begin{array}{l}94 \pm 3 \\
92 \pm 6\end{array}$ & $\begin{array}{r}100 \pm 0 \\
91 \pm 7\end{array}$ \\
\hline 2 & $\begin{array}{l}\text { Round } \\
\text { Conical }\end{array}$ & $\begin{array}{l}65 \pm 22 \\
53 \pm 17\end{array}$ & $\begin{aligned} 100 \pm 0 \\
76 \pm 19\end{aligned}$ & $\begin{array}{r}100 \pm 0 \\
60 \pm 7\end{array}$ & $\begin{array}{r}100 \pm 0 \\
92 \pm 2\end{array}$ & $\begin{aligned} 100 & \pm 0 \\
80 & \pm 20\end{aligned}$ & $\begin{array}{l}94 \pm 5 \\
92 \pm 2\end{array}$ & $\begin{array}{r}100 \pm 0 \\
95 \pm 5\end{array}$ & $\begin{aligned} 79 & \pm 21 \\
100 & \pm 0\end{aligned}$ \\
\hline
\end{tabular}

Values are the mean \pm s.e.m. for 10 or 4 observations, i.e. 5 or 2 horns in a tube and 2 tubes.

The purity of the epithelial fraction was assessed by comparing the $\left[{ }^{3} \mathrm{H}\right]$ thymidine labelling indices (see Smith et al., 1970) in smears of isolated epithelial nuclei with those of the epithelium and stroma in sections of the corresponding unvortexed uterine horn. Two experiments were conducted for each hormone treatment and the percentage of cells derived from the epithelium was calculated to be $90,81,65$ and 81 for uteri in Groups C, O, P and PO, respectively. Haemocytometer counts of the number of nuclei in 5 epithelial fractions prepared from Group $\mathrm{C}$ indicated that $(2.44 \pm 0.2) \times 10^{6}$ luminal epithelial cells were removed per uterine horn. This compares favourably with the estimate of $1.78 \times 10^{6}$ epithelial cells per uterine horn obtained by counting epithelial cells in histological sections, taking into account the degree of non-epithelial contamination estimated by $\left[{ }^{3} \mathrm{H}\right]$ thymidine labelling.

\section{Microscopic studies}

'Residual' uterus. Plate 1 shows transverse sections of uterine horns before (Fig. 1) and after (Fig. 2) removal of the epithelium; these sections are typical of those routinely examined during the development of this method. In no section examined was there evidence of gross damage to either the stromal surface or the peritoneal epithelium. In addition, a large number (46) of specimens was examined by transmission and scanning electron microscopy (Pl. 1, Figs 3-5). 
After removal of the epithelium, the basement membrane remained intact (Pl. 1, Fig. 3), endothelial cells were intact and the superficial stromal cells, whilst somewhat damaged, still contained whole nuclei. In contrast, when the epithelium was removed in a solution of $10 \mathrm{mM}$-Tris- $\mathrm{HCl}$ (pH 7.4) plus 1 mM-EDTA (instead of PBS), the stromal nuclei were also ruptured (Pl. 1, Fig. 4).

Examination of the entire uterine luminal surface indicated that the epithelium was removed from the whole surface, and not simply from discrete areas (Pl. 1, Fig. 5). The micrograph illustrated shows two small tears in the basement membrane, demonstrating the ease with which such areas may be recognized; in only one other case was such damage observed.

Epithelial nuclear fraction. The use of several different solutions during vortexing did not alter the extent of epithelial cell removal. However, the most satisfactory nuclear preparations (Pl. 1, Fig. 6) were obtained when $0.25 \mathrm{M}$-sucrose, $3 \mathrm{mM}^{-\mathrm{CaCl}_{2}}$ and $0.7 \%(\mathrm{v} / \mathrm{v})$ Nonidet $\mathbf{P} 40$ (BDH, Poole, Dorset) was used as the buffer. The DNA content of nuclei prepared in this manner (from Group C) was $6.2 \pm 0.61$ (s.e.m.) pg/nucleus. This is close to the value of 6.4 $\mathrm{pg} /$ nucleus obtained by averaging several estimates in the literature (Shapiro, 1973), and indicates that there is no substantial fragmentation of nuclei during preparation.

Use of various other solutions resulted in a nuclear pellet which contained (a) ruptured nuclei (10 mM-Tris-HCl (pH 7.4) + 1 mM-EDTA; PBS + 0.7\% Nonidet) or (b) other subcellular organelles (PBS; $0.25 \mathrm{M}$-sucrose $+3 \mathrm{mM}-\mathrm{CaCl}_{2}$ ). Collagen was apparent in only 2 out of the 34 nuclear pellets examined. Homogenization of the epithelial fraction before low-speed centrifugation, or high-speed centrifugation in $2 \mathrm{M}$-sucrose, did not markedly improve the purity of the nuclear fraction, as determined by electron microscopy.

\section{Discussion}

A simple method for separating the luminal epithelium from the mouse uterus has been presented. No other method has been developed specifically for application to uteri in a variety of hormonal states, which alter the characteristics of the tissues (reviewed by Finn \& Porter, 1975), and no previous report has included estimates of both the extent of epithelial removal and the purity of the resultant fraction. Our technique was developed for use with animals receiving no hormone treatment (Group C) or combinations of progesterone and oestrogen (Groups P, PO and $\mathrm{O}$ ); the importance of employing optimal conditions was particularly apparent for Groups $\mathrm{O}$ and $P O$. For routine use, it is suggested that 2 uterine horns and 5 glass balls should be vortexed in a round-bottomed tube for $2 \mathrm{~min}$. Under these conditions, $79-100 \%$ of the epithelium was removed. The purity of the resulting epithelial fractions was shown by $\left[{ }^{3} \mathrm{H}\right]$ thymidine labelling to be $65-90 \%$, values which compare well with the estimates of $75-85 \%$ and $80-100 \%$ obtained by Smith et al. (1970) and Pollard \& Martin (1975) respectively (see 'Introduction').

Extensive histological examination demonstrated that the basement membrane remained intact, suggesting that any contamination of the epithelial fraction by insoluble components originates from the cut edges of the uteri, and not by rupture of the stromal surface. This problem is common to all epithelial separation methods, as is that of contamination by soluble material from the other tissues. However, vortexing does not produce the gross stromal damage that is seen in histological sections after scraping or shearing the uteri.

The epithelial fraction described in the present report consists of a suspension of intact nuclei together with the remaining epithelial cell constituents. However, the cell nucleus plays a major role in the induction of the response to steroid hormones (Chan \& O'Malley, 1976), and the present study was therefore extended to the purification of nuclei from the epithelial fraction. The composition of the solution used for the removal of the epithelium was shown to be critical for both the integrity of the nuclei and the purity of the final nuclear pellet.

The epithelial separation procedure is therefore relatively quick and simple, requires no 
specialized apparatus and gives reproducible results between different operators during routine use in this laboratory. The method can be successfully used to remove the epithelium from uteri of animals undergoing a variety of hormone treatments, and it should therefore prove useful for studies of hormone-induced changes occurring at the molecular level in the uterine tissues.

We thank Ms Rosemary Johnson for histology and Mr Richard Newman of the ICRF Electron Microscope Unit for preparing the electron micrographs. S4 and S600 scanning electron microscopes were used by permission of the Biological Microprobe Laboratory, Cambridge, and the Cambridge Instrument Company respectively. B.F. was in receipt of a Bursary from the Imperial Cancer Research Fund.

\section{References}

Alberga, A. \& Baulieu, E.-E. (1968) Binding of estradiol in castrated rat endometrium in vivo and in vitro. Molec. Pharm. 4, 311-321.

Chan, L. \& O'Malley, B.W. (1976) Mechanism of action of the sex steroids. N. Engl. J. Med. 294, 1322-1328.

Cohen, A.L. (1974) Critical point drying. In Principles and Techniques of Scanning Electron Microscopy, Vol. 1, pp. 44-112. Ed. M. A. Hayat. Van Nostrand Reinhold, New York.

Dulbecco, R. \& Vogt, M. (1954) Plaque formation and isolation of pure lines with poliomyelitis viruses. $J$. exp. Med. 99, 167-199.

Finn, C.A. \& Porter, D.G. (1975) The Uterus. Elek Science. London.

Heald, P.J., Govan, A.D.T. \& O'Grady, J.E. (1975) A simple method for the preparation of luminal epithelium and stromal cells from rat uterus. J. Reprod. Fert. 42, 593-595.

Hill, B.J. \& Whatley, S. (1975) A simple rapid microassay for DNA. FEBS Letters 56, 20-23.

Kelley, R.O., Dekker, R.A.F. \& Bluemink, J.G. (1974) Ligand-mediated osmium binding. In Principles and Techniques of Scanning Electron Microscopy, Vol. 4, pp. 57-99. Ed. M. A. Hayat. Van Nostrand Reinhold, New York.

King, R.J.B. \& Gordon, J. (1966) The localisation of $\left[6,7-{ }^{3} \mathrm{H}\right]$ oestradiol- $17 \beta$ in rat uterus. J. Endocr. 34, $431-437$.
Lee, A.E. (1973) The effect of oestrogen and its antagonists on the mouse uterus. Ph.D. thesis, University of London.

Martin, L. \& Finn, C.A. (1968) Hormonal regulation of cell division in epithelial and connective tissues of the mouse uterus. J. Endocr. 41, 363-371.

Martin, L., Finn, C.A. \& Trinder, G. (1973) Hypertrophy and hyperplasia in the mouse uterus after oestrogen treatment: an autoradiographic study. $J$. Endocr. 56, 133-144.

Pollard, J.W. \& Martin, L. (1975) Cytoplasmic and nuclear non-histone proteins and mouse uterine cell proliferation. Molec. cell. Endocr. 2, 183-191.

Shapiro, H.S. (1973) Deoxyribonucleic acid content per cell of various organisms. In Handbook of Biochemistry, section H-112. Ed. H. A. Sober. The Chemical Rubber Co., Cleveland, Ohio.

Smith, J.A., Martin, L., King, R.J.B. \& Vertes, M. (1970) Efsects of oestradiol-17\% and progesterone on total and nuclear protein synthesis in epithelial and stromal tissues of the mouse uterus, and of progesterone on the ability of these tissues to bind oestradiol-17ß. Biochem. J. 119, 773-784.

Received 13 December 1978 